\title{
HUBUNGAN IMT DENGAN KADAR KOLESTEROL PADA KARYAWAN WANITA DI RUMAH SAKIT ADVENT BANDAR LAMPUNG
}

\author{
Arjuna Aldito, Jeanny Rantung \\ Fakultas Ilmu Keperawatan, Universitas advent Indonesia \\ Email: Arjunaaldito90@gmail.com
}

\begin{abstract}
ABSTRAK
Kolesterol adalah salah satu golongan lemak yang bersifat atarogenik atau mudah menempel dan membentuk plak pada dinding pembuluh darah, mengakibatkan kelebihan kolesterol dalam darah (hiperkolesterolemia). Kondisi hiperkolesterolemia sangat beresiko terkena penyakit kardiovaskular. Penyakit kardiovaskular atau yang dikenal dengan The silent killer masih menjadi penyebab nomor satu kematian didunia. Adapun tujuan dari penelitian ini adalah untuk mengetahui hubungan IMT dengan kadar kolesterol. Penelitian ini menggunakan desain cross sectional. Pengambilan sampel dilakukan secara non probability sampling dengan menggunakan teknik purposive sampling Pengumpulan data dilakukan di Rumah Sakit Advent Bandar Lampung dengan jumlah responden sebanyak 40 orang karyawan wanita. Uji analisis bivariat menggunakan uji statistic Pearson Product-Moment Correlation. Hasil analisis statistik menunjukkan tidak ada hubungan yang signifikan antara IMT dan kadar kolesterol ( $p$ value 0,431) pada wanita dewasa di Rumah Sakit Advent Bandar Lampung. Saran yang dapat diberikan adalah dengan menambah jumlah responden untuk penelitian selanjutnya, atau melakukan penelitian tentang faktor-faktor lain yang dapat mempengaruhi peningkatan kadar kolesterol dalam darah.
\end{abstract}

Kata kunci: Indeks Massa Tubuh, Kolesterol total

\section{ABSTRACT}

Cholesterol is one of the groups of fat that is atarogenic or easily sticks and forms plaque on the walls of blood vessels, resulting in excess cholesterol in the blood (hypercholesterolemia). Hypercholesterolemic conditions are very risky for cardiovascular disease. Cardiovascular disease or what is known as The silent killer is still the number one cause of death in the world. The purpose of this study was to determine the relationship between BMI and cholesterol levels. This study used a cross sectional design. Sampling was carried out by non-probability sampling using purposive sampling technique. Data collection was carried out at the Bandar Lampung Adventist Hospital with a total of 40 female employees as respondents. The bivariate analysis test used the Pearson Product-Moment Correlation statistical test. The results of statistical analysis showed that there was no significant relationship between BMI and cholesterol levels ( $p$ value 0.431) in adult women at the Bandar Lampung Adventist Hospital. Suggestions that can be given are to increase the number of respondents for further research, or to conduct research on other factors that can affect the increase in cholesterol levels in the blood.

Key words: body mass index, total cholesterol 


\section{PENDAHULUAN}

Timbulnya penyakit akibat penurunan fungsi sel dan juga organ semakin banyak ditemukan disemua kalangan masyarakat dapat disebabkan oleh banyak faktor, salah satunya adalah kelebihan kolesterol di dalam tubuh. Apabila seseorang memiliki kadar kolesterol dalam darah diatas $200 \mathrm{mg} / \mathrm{dL}$ memiliki dampak buruk terhadap kesehatan dan memiliki resiko tinggi terkena penyakit jantung dan pembuluh darah. (Sa'adah, 2018).

Angka kematian didunia diperkirakan akan meningkat hingga mencapai 2,6 juta orang setiap tahun, yang mendominasi dari angka kematian ini adalah penyakit jantung dan stroke yang disebabkan oleh peningkatan kadar kolesterol dalam darah. Tercatat bahwa penyakit kolesterol total tertinggi diduduki oleh wilayah Eropa yang mencapai angka 54\% baik laki- laki ataupun perempuan, kemudian wilayah Amerika 48\%, untuk Asia Tenggara 29,0\% dan 22,6\% untuk wilayah Afrika (WHO, 2013).

Prevelensi peningkatan kolesterol di Indonesia pada kelompok usia 25-34 tahun adalah $9,3 \%$, bertambahnya usia berpengaruh pada peningkatan kolesterol hingga $15,5 \%$ pada kelompok usia 55-64 tahun (Depkes, 2013). $80 \%$ pasien meninggal mendadak akibat serangan jantung, dan 20\% tidak menimbulkan gejala sebelumnya. Konsumsi makanan yang mengandung kolesterol dalam jumlah yang berlebihan, dapat menyebabkan kadar kolesterol dalam darah melebihi batas normal (Indriyana, 2018). Kolesterol adalah salah satu golongan dari lemak (lipida) padat, kolesterol bersifat aterogenik atau sangat mudah menempel lalu membentuk plak pada dinding pembuluh darah.

Kolesterol yang diproduksi oleh tubuh terdiri dari kolesterol HDL (High Density Lipoprotein) yang biasa disebut dengan kolesterol baik dan kolesterol LDL (Low Density Lipoprotein) disebut kolesterol jahat. Kelebihan kadar kolesterol didalam darah disebut dengan hiperkolesterolemia (Yoeantarafara, 2017).

$$
\text { Dari beberapa faktor yang }
$$
mempengaruhi peningkatan kolesterol dalam darah terdapat salah satu faktor yang mempengaruhi kadar kolesterol total dalam tubuh yaitu Indeks Massa Tubuh (IMT). Kolesterol total pada laki-laki dan perempuan semakin meningkat dengan meningkatnya nilai IMT (Suatra, 2018). IMT adalah sebuah indeks nilai yang didapatkan dari pengukuran berat badan dalam satuan kilogram (kg) dibagi dengan tinggi badan dengan satuan meter kuadran $\left(\mathrm{m}^{2}\right)$, indeks ini digunakan untuk mengkategorikan seseorang tergolong kedalam kategori berat badan kurang, normal atau lebih (Humaera, 2017). Kategori IMT secara umum, IMT $<18,5$ berat badan kurang (underweight), IMT 18,5-22,9 berat badan normal, IMT 23,024,9 kelebihan berat badan (overweight), IMT $>25$ sebagai obesitas (Sitepu, 2017).

Perilaku yang berubah mengikuti jaman modern saat ini masyarakat lebih condong kepada sesuatu yang praktis dan instan. Wanita dewasa enggan melakukan pola hidup sehat. Obesitas atau berat badan tidak ideal didapat dari pola hidup yang tidak sehat. Obesitas didefinisikan sebagai kondisi kelebihan berat badan akibat akumulasi lemak 
yang merugikan kesehatan (Sinurat, 2019). Dalam penelitian yang dilakukan oleh Siagian (2016) di Rumah Sakit Advent Bandar Lampung tentang pengaruh penerapan modifikasi perilaku sehat terhadap kesehatan, didapati bahwa sebelum dan sesudah dilakukan penerapan pola hidup sehat dan olahraga adanya perbedaan yang signifikan antara gula darah dengan kolesterol sebelum dan sesudah dilakukan intervensi.

Berdasarkan data di atas maka peneliti tertarik untuk melanjutkan penelitian, dengan melihat hubungan IMT dengan kadar kolesterol pada karyawan wanita di rumah sakit Advent Bandar Lampung.

\section{METODE PENELITIAN}

Pada penelitian ini peneliti menggunakan design cross-sectional yang bersifat observational analitik, agar dapat menganalisis hubungan variable. Pengambilan sampel dilakukan secara non probability sampling dengan menggunakan teknik purposive sampling. Penelitian ini dilakukan di Rumah Sakit Advent Bandar Lampung pada tanggal 23-24 juli 2020, melibatkan 40 orang wanita dewasa yang merupakan karyawan Rumah Sakit Advent Bandar Lampung yang memiliki IMT diatas normal. Responden penelitian juga memenuhi kriteria inklusi dan bersedia mengisi informed consent. Pengumpulan data dilakukan dengan melakukan pengukuran Berat Badan (BB) dan Tinggi Badan (TB), serta melakukan pengukuran kadar kolesterol darah dengan menggunakan strip.
Data kemudian diolah dan dianalisa menggunakan analisa univariat untuk mengetahui karakteristik responden. Uji analisis bivariat menggunakan uji statistic Pearson Product-Moment Correlation untuk mengetahui adakah hubungan IMT dengan kadar kolesterol

Tabel 1: Kategori Index Massa Tubuh (IMT)

\begin{tabular}{|c|c|}
\hline Kategori & Nilai \\
\hline Under wight & $<18,5$ \\
\hline Normal & $18,5-24,9$ \\
\hline Over wight & $25-29,9$ \\
\hline Obesitas & $>30$ \\
\hline \multicolumn{2}{|c|}{ World Health Organization (WHO) 2016} \\
\hline \multicolumn{2}{|c|}{$\begin{array}{l}\text { Standart kadar kolesterol dalam dara } \\
\text { terdapat pada tabel berikut. }\end{array}$} \\
\hline \multicolumn{2}{|c|}{ Tabel 2: Kadar kolesterol dalam darah } \\
\hline Kategori & Nilai \\
\hline Normal & $<200 \mathrm{mg} / \mathrm{Dl}$ \\
\hline Ambang batas & $200-239 \mathrm{mg} / \mathrm{dL}$ \\
\hline Tinggi & $240 \mathrm{mg} / \mathrm{dL}$ \\
\hline
\end{tabular}

\section{HASIL}

Penelitian ini dilakukan di Rumah Sakit Advent Bandar lampung pada tanggal 2324 juli 2020 dengan jumlah responden adalah 40 wanita dewasa karyawan Rumah Sakit Advent Bandar Lanpung yang memiliki IMT diatas normal dan juga dikelompokkan berdasarkan usia. Setelah dilakukan validasi data menggunakan uji statistic Pearson Product-Moment Correlation maka didapati data- data sebagai berikut: 
Tabel 3 Distribusi Karakteristik Responden Berdasarkan Usia $(n=40)$

\begin{tabular}{ccc}
\hline Usia & $\mathrm{n}$ & $\%$ \\
\hline $25-30$ & 3 & 7.5 \\
$31-40$ & 19 & 47.5 \\
$41-50$ & 15 & 37.5 \\
$51-60$ & 3 & 7.5 \\
Total & 40 & 100 \\
\hline
\end{tabular}

Berdasarkan distribusi karakteristik usia pada tabel 3 menunjukkan bahwa usia 2530 tahun berjumlah 3 orang (7,5\%), usia 31- 40 tahun berjumlah 19 orang (47.5\%), usia 41-50 tahun berjumlah 15 orang $(37,5 \%)$, usia 51-60 tahun berjumlah 3 orang $(7,5 \%)$.

Tabel 4 Distribusi Karakteristik Berdasarkan Status Pernikahan $(n=40)$

\begin{tabular}{ccc}
\hline Status & N & $\%$ \\
\hline Menikah & 33 & 82 \\
Janda & 3 & 7,5 \\
Belum Menikah & 4 & 10 \\
Total & 40 & 100 \\
\hline
\end{tabular}

Distribusi karakteristik responden berdasarkan status pernikahan pada tabel 4 menunjukkan bahwa yang menikah berjumlah 33 orang $(82 \%)$, janda berjumlah 3 orang (7.5\%), belum menikah berjumlah 4 orang $(10 \%)$.

Tabel 5 Distribusi Karakteristik Responden Berdasarkan Pendidikan $(\mathrm{n}=40)$

\begin{tabular}{ccc}
\hline Pendidikan & $\mathrm{N}$ & $\%$ \\
\hline SMA & 3 & 7,5 \\
D3 & 5 & 12,5 \\
\hline
\end{tabular}

\begin{tabular}{ccc}
\hline S1 & 31 & 77,5 \\
S2 & 1 & 2,5 \\
Total & 40 & 100 \\
\hline
\end{tabular}

Distribusi karakteristik responden berdasarkan pendidikan pada tabel 5 menunjukkan bahwa yang berpendidikan SMA sebanyak 3 orang (7,5\%), D3 sebanyak 5 orang (12,5\%), S1 sebanyak 31 orang $(77,5 \%)$, S2 sebanyak 1 orang $(2,5 \%)$.

Tabel 6 Distribusi Karakteristik Responden Berdasarkan IMT $(\mathrm{n}=40)$

\begin{tabular}{ccc}
\hline Kategori & $\mathrm{N}$ & $\%$ \\
\hline Overweigh & 25 & 62,5 \\
Obesitas & 15 & 37,5 \\
Total & 40 & 100 \\
\hline
\end{tabular}

Distribusi karakteristik responden berdasarkan IMT pada tabel 6 menunjukkan bahwa yang over weight sebanyak 25 orang $(62,5 \%)$, obesitas sebanyak 15 orang $(37,5 \%)$.

Tabel 7 Distribusi Karakteristik Responden Berdasarkan Kadar Kolesterol $(n=40)$

\begin{tabular}{ccc}
\hline Kategori & $\mathrm{N}$ & $\%$ \\
\hline$<200 \mathrm{mg} / \mathrm{Dl}$ & 17 & 42,5 \\
$200-239 \mathrm{mg} / \mathrm{Dl}$ & 17 & 42,5 \\
$>240 \mathrm{mg} / \mathrm{Dl}$ & 6 & 15 \\
Total & 40 & 100 \\
\hline
\end{tabular}

Berdasarkan tabel diatas menunjukkan bahwa yang memiliki kolesterol $<200 \mathrm{mg} / \mathrm{dl}$ atau termasuk dalam batas normal sebanyak 17 orang (42,5\%), yang memiliki kadar kolesterol 200-239 mg/dl atau yang disebut dengan 
border line sebanyak 17 orang (42,5\%), dan yang memiliki kolesterol $>240 \mathrm{mg} / \mathrm{dl}$ atau kolesterol tinggi berjumlah 6 orang (15\%).

Tabel 8 Hasil Analisis Pearson Product Moment terhadap hubungan IMT dengan kadar Kolesterol

\begin{tabular}{llrr}
\hline \multicolumn{4}{c}{ Correlations } \\
\hline & \multicolumn{1}{c}{ IMT } & \multicolumn{1}{c}{ Kolesterol } \\
\hline IMT & $\begin{array}{l}\text { Pearson } \\
\text { Correlation }\end{array}$ & 1 & $-0,128$ \\
\cline { 2 - 3 } & $\begin{array}{l}\text { Sig. (2- } \\
\text { tailed) }\end{array}$ & & 0,431 \\
& $\mathrm{~N}$ & 40 & 40 \\
\hline
\end{tabular}

Tabel diatas menunjukkan bahwa tidak ada hubungan antara IMT dan Kolesterol ditunjukkan oleh nilai signifikansi 0,431 (p value $>0,05)$. Jika kita melihat dari nilai pearson correlation maka r:-0,128 berada antara $(0,00-0,20)$ yakni tidak ada hubungan atau korelasi.

\section{PEMBAHASAN}

Jadi setelah dilakukan uji statistik terhadap hasil penelitian yaitu "Hubungan IMT Dengan Kadar Kolesterol Pada Karyawan Wanita di Rumah Sakit Advent Bandar Lampung", maka didapati bahwa tidak ada hubungan atau korelasi antara IMT diatas normal dengan kadar kolesterol dalam darah. Dengan hasil uji signifikansinya adalah 0,431 > 0,05 dan nilai korelasi pearsonnya adalah r:0,128 berada antara $(0,00-0,20)$ yakni tidak ada hubungan atau korelasi.

Penelitian yang sama yang dilakukan oleh Sinurat (2019) mengatakan bahwa tidak terdapat hubungan yang signifikan antara indeks massa tubuh dengan kadar kolesterol total dalam darah.

Peningkatan kolesterol dalam darah tidak hanya dipengaruhi oleh IMT yang meningkat, namun masih banyak faktor yang mempengaruhi seperti yang dikemukakan oleh Sitepu (2017) bahwa berdiam diri atau kurangnya aktivitas fisik yang tidak seimbang dengan asupan kolesterol yang tinggi dari pola makan sehari- hari dapat mempengaruhi peningkatan kolesterol dalam darah.

Kandungan lemak pada tubuh manusia dapat meningkat seiring bertambahnya usia seseorang. Usia yang semakin dewasa tentunya mempengaruhi perubahan hormon yang memicu lemak visceral. Pada wanita terdapat perbedaan pengontrolan energi dan lemak tubuh, karena energi yang berlebih diubah menjadi lemak simpanan (Pradono, 2016).

Hormon estrogen yang terdapat pada wanita memiliki peran untuk menjaga keseimbangan kolesterol, yaitu dengan cara membatasi asam lemak masuk kembali kehati dan menyebabkan akumulasi diacylyceroi sehingga terjadilah peningkatan LDL dalam darah (Palmisano, 2017).

AHA (2016) mengungkapkan bahwa wanita usia produktif cenderung memiliki kadar kolesterol yang lebih rendah dari pria, pada saat wanita memasuki fase menopause maka kadar kolesterol dalam darah akan meningkat lebih tinggi dari pria ini diakibatkan hormone estrogen yang tidak stabil (Musdalifa, 2017).

Dalam tulisannya Musdalifah (2017) selain kurangnya aktivitas fisik maka ada faktor lain yang meningkatkan kolesterol diantaranya 
adalah: usia, stress, merokok dan faktor keturunan.

\section{KESIMPULAN}

Pada penelitian ini dapat disimpulkan bahwa tidak ada hubungan yang signifikan antara IMT dan kadar kolesterol (p value 0,431 ) pada wanita dewasa di Rumah Sakit Advent Bandar Lampung.

\section{SARAN}

Setelah hasil penelitian yang menunjukkan tidak ada hubungan antara IMT dengan kolesterol dalam darah maka peneliti memberikan saran untuk peneliti selanjutnya agar menambah jumlah responden dalam mewakili populasi ataupun dapat meneliti tentang faktor- faktor lain yang dapat mempengaruhi peningkatan kadar kolesterol dalam darah.

\section{REFERENSI}

American Heart Association. (2016). American Heart Association Recommendation for Physical Activity in Adults. http://www.guidesreprts/2016-0829-aha-chatbook-2016.

Departemen Kesehatan Republik Indonesia. Riset Kesehatan Dasar Jakarta: Badan Penelitian dan Pengembagan Kesehatan, Departemen Kesehatan Republik Indonesia; 2013.

Humaera, Z ., Sukandar, H., Rachmayati, S., 2017. Korelasi Indeks Massa Tubuh dengan Profil Lipid pada Masyarakat di Jatinangor tahun 2014. JSK, 3 (1), 12-17.
Indriyana, P, dkk (2018). Pengaruh Therapeutic Lifestyle Change Terhadap Pengaturan Diet, Aktivitas Fisik, dan Kadar Kolesterol Total Pasien Hiperkolesterolemia di Puskesmas. Jurnal Ilmu Keperawatan (2018) 6:1 ISSN: 2338-6371, e-ISSN 2550-018x.

Musdalifa, Wicaksono, S., Tien et al (2017) Hubungan Indeks Massa Tubuh dengan Kadar Kolesterol Total pada Staff dan Guru SMA Negeri 1 Kendari. E-ISSN, 4(2), 24430218.

Palmisano B.T., Zhu L., Stafford J.M (2017). Rale of Estrogen In The Regulation of Liver Lipid Metabolism. Spinger International Publishing AG, 227-256

Pradono Julianti, Riyadi Hadi., et al (2016). Hubungan Obesitas Sentral Dengan Profil Lipid pada Orang Dewasa umur 26-65 tahun di Kota Bogor. Journal of The Indonesian Nurtision Association. e-ISSN 2528-5874.

Sa'adah, W, dkk 2018. Hubungan Pengetahuan Tentang Bahan Makanan Sumber Lemak dengan Tingkat Konsumsi Lemak dan Kadar Kolesterol Total Pasien Hiperkolesterolemia Anggota Persatuan Diabetisi. Jurnal Gizi Prima, Vol.3, Edisi.1, Maret 2018, pp. 35-42. ISSN: 2656-2480 (online).

Siagian. E (2016). Pengaruh Penerapan Modifikasi Perilaku Sehat Terhadap Faktor Resiko DM Tipe 2. Jurnal Skolastik Keperawatan vol.02. No. 1 2016.

Sinurat, R., \& Elon, Y. (2019). Hubungan BMI dengan Kadar Kolesterol Total Darah pada Wanita Dewasa. Journal Nutrix Volume 3, No.2, Oktober 2019. e-ISSN 2580-6432 
Sitepu W, Indah (2014). Hubungan Antara Indeks Massa Tubuh dengan Kadar Profil Lipid pada pasien dewasa di bagian penyakit dalam Rumah Sakit PHC Surabaya.repository.wima.ac.id

Suatra. Nugraha Gde I Ketut. (2018). Hubungan Body Mass Index (BMI) Dengan Kadar Kolesterol Total Darah Pada Populasi Dewasa di Dusun Tanjung, Kulon Progo, Yogyakarta.

WHO. (2016). Body Mass Index (BMI) Classification. Available at hppts://www.who.int.

World Health Organisation (WHO). 2013. Obesity and Overweight. http://www.who.int/mediacentre/fact sheets/fs311/en/index.html diakses pada 20 April 2020.

Yoeantafara, A. (2017). Pengaruh Pola Makan Terhadap Kadar Kolesterol Total. JURNAL MKMI, Vol. 13 No. 4, Desember 2017. 